\title{
Research on Experiential Marketing Model Based on Consumer Demand LiMing Zhang ${ }^{1}$ \\ ${ }^{1}$ Qujing Normal University, yunnan qujing city kirin sanjiang avenue, 655011 308053539@qq.com
}

\section{Keywords: Marketing; Experience marketing; Marketing model}

\begin{abstract}
With the development of social economy, the change of consumer demand and the formation of consumption preferences, the traditional marketing way has not satisfied the needs of enterprises, and can not help enterprises achieve their business goals better. In order to improve market share and improve customer satisfaction, enterprises need to try new marketing models. Based on the analysis of experiential marketing, experiential marketing and the attentions, this paper puts forward and analyzes the application of experiential marketing to enterprises.

With the coming of experience economy, in order to consolidate the market position, enterprises need to better meet the growing psychological needs and personalized needs of consumers, and provide valuable experience to consumers in marketing, so that experiential marketing can become a new marketing mode of enterprises. Experience marketing is "enterprise according to the characteristics of the emotional needs of consumers, combined with the properties of products and services to planning a specific atmosphere of marketing activities, to allow consumers to participate in and get a good and deep experience, to the greatest extent possible to meet their emotional needs, to further expand a new marketing mode of selling products and services." [1] to experience marketing products and services as the core, in order to improve the enterprise and the Consumer Association, closer to the distance between the two, the interactive marketing, emphasizing the consumer's sense of participation, experience to meet the needs of consumers, so as to enhance the enterprise value, to achieve a win-win business with consumers. Therefore, experiential marketing is different from traditional marketing mode, which is more suitable for modern consumers to pursue mental level needs based on material and physiological needs.
\end{abstract}

\section{The Role of Experience Marketing}

Deepen the Cognition of the Product. In order to improve the sales of the product, the enterprise should first let the consumer approve the product. In the past, through traditional promotion, such as advertising, personal selling, etc., the product information was transmitted, and the interaction between enterprises and consumers was strengthened. But consumers' cognition of products is limited, and they cannot identify products in time and effectively. In experiential marketing, enterprises pay attention to consumers' experience needs. Through personal experience, they can perceive product differentiation and deepen their cognition of products, so as to better differentiate products quickly.

Improve the reliability of the product. With the diversification of marketing channels, the use of various means of competition, especially the emergence of unfair competition, allowing consumers to reduce the credibility of enterprises and products, such as door-to-door salesmen have been shut out, such as new products, new business, because consumers can not, do not believe, can lead to the purchase behavior. And let consumers fully experience in the purchase process, actually feel the product and the consumer experience, let consumers feel closer to the product value and function, so as to enhance the credibility of the product and win the consumer market.

Enhance the Sense of Participation of Consumers. The consumer is the decision maker of the market development, and the enterprise is the promoter of the market development. The management of enterprises is to carry out marketing activities at the core of the market demand under the consumer centered marketing concept. In traditional marketing, consumers are less involved in the design, production and sales of products, and even lack of participation. Through consumer experience, such as integrating consumer needs into product design, caters to the interests 
and interests of consumers, and realizes interaction between service and product experience, it improves their sense of participation and makes it produce desire for purchase.

Improve the Effect of Communication. In the past, the product information is mainly through the mass media to reach the consumer, and the product and the consumer should be connected through media intermediaries. Experiential marketing makes the consumer close to the product and the enterprise. In the process of contact, it is easy to produce emotional resonance, thus affecting the consumption psychology and guiding the consumption. At the same time, when the product meets the consumer experience needs and realizes the experience value, consumers will be willing to share with their family members and friends quickly, and actively promote and promote the communication effect, which is conducive to the establishment of product image and the formation of good word of mouth.

Improve Customer Satisfaction and Loyalty. In experiential marketing, due to the full participation of consumers, strengthen the awareness of the product, so that consumers understand the new products, new business and operation methods, can better physical products and intangible products to the consumer products, greatly enhance the credibility, strengthen the sense of trust, greatly shorten the consumer information collection and evaluation the purchase decision process in time, reduce the phenomenon of back or return after purchase. In the experience marketing, the interaction between the enterprise, the product and the consumer improves the customer satisfaction to a certain extent, and realizes the promotion of customer loyalty.

\section{The Notices of Experience Marketing}

The rational design of the consumption experience. In order to allow consumers to experience marketing really feel the charm of products and services, to reflect the experience value, enterprise marketing experience to deal with the whole scheme, experience the process carefully and reasonable planning and design, and always pay attention to the experience of each link and the details, let the experience show the characteristics of the product, in line with the needs of the consumer experience. Let consumers experience the joy and satisfaction.

Customized Products and Services. In order to experiential marketing based on satisfying consumers for products and services of the functional requirements and physiological needs, to better meet the special needs of consumers, enterprises often take customized products and services, tailored for consumers with personalized products or to provide comprehensive services, in order to meet the special needs of consumers, so that the value of products and services to maximize the promotion.

The Full Integration of the Experience Components. Experiential marketing has become a new marketing mode for many enterprises. However, due to the influence of marketing concept and environment, some marketers believe that experiential marketing is just a way to improve sales volume, especially in service. With the fierce market competition, the homogenization of products, the willingness of enterprises to imitate and plagiarize and other problems appear. It is more necessary for enterprises to increase experience components through experience design, highlight the individuation of products and services, form consumption preference and stimulate consumption desire.

Emphasis on Customer and Social Interests. The marketing management philosophy mainly solves the three aspects of the interests of the enterprise, the consumer and the society. And modern marketing takes consumers and social interests as the fundamental purpose and responsibility of the enterprise, and this basic guiding ideology is also applicable to experience marketing. When researching and developing experiential marketing, enterprises should give full consideration to experience consumption environment, product service characteristics, experience consumption process, experience measures and social impact factors, so as to make consumers truly satisfied, enhance customer loyalty and customer value.

Catering to the Psychological Needs of Consumers. The ultimate goal of marketing is to meet consumer demand. With the improvement of the level of consumer demand, the impact of psychological demand on its purchasing behavior is becoming more and more important. In view of 
the overall concept of products, enterprises should pay attention to the development and design of form products and extended products, and make products meet consumer psychological needs in product experience, create valuable consumption experience, help enterprises to tap marketing opportunities and expand new markets.

\section{Analysis of Experience Marketing Model}

Sensory Experience Model. The sensory experience is "through the vision, the hearing, the touch and the sense of smell to establish the sensory experience." Its main purpose is to create the experience of perceptual experience. [2]with the rapid development of products, consumers have more choices for products. Enterprises can't achieve satisfactory results only through visual and auditory sensory stimulation. Experience in marketing, in order to let consumers have a more vivid perception of the characteristics of products, marketing needs to mobilize consumers of the sense organs, such as vision to help consumers identify the product appearance; auditory perception phenomenon atmosphere, effective communication; tactile material; taste and smell can cause Lenovo, identification products etc.. Add sensory elements to the product, improve the sense of sensory experience and enhance the vitality of the product.

Entertainment Experience Model. The entertainment experience marketing is the experience marketing aimed at satisfying the customer's entertainment activities, and it is effective to achieve the marketing goal by pleasing the customer. [3] consumers hope that every time they consume is done in a pleasant and relaxed environment, and they can enjoy the pleasure of consumption, so entertainment experience marketing is accepted and loved by businesses and consumers. The enterprise marketing entertainment experience, one is to choose the form of entertainment products and to match; two is a form of entertainment, entertainment design can be accepted by consumers; the three is to sell products, and entertainment in the form of combination, so that consumers feel good consumer experience

Emotional Experience Model. When enterprises emphasize the functional needs of consumers, they should also attach importance to the emotional needs of consumers. Through emotional experience design, consumers will experience a pleasant experience of consumption. The emotional experience of marketing is the enterprise in the marketing experience, in order to mobilize consumer sentiment, combined with the product characteristics, analysis of the emotional needs of the consumers, will integrate emotional elements into the whole process of marketing experience, so that both sides can empathize, meet consumers' psychological demands and emotional needs, realize enterprise profit model of experiential marketing. Enterprises should fully understand the needs of consumers, the design of emotional experience into the experience in marketing, in order to achieve the moving situation, and actively guide consumers' positive emotional experience, positive emotion, resonate, stimulate the desire to buy, the purchase behavior.

Situational Experience Model. Scene experience is also known as the atmosphere experience, refers to "in marketing activities, business according to the different psychological demands of consumers, through various means to create a new mood, can be fully released the scene or atmosphere for the customer, in order to obtain the value effect of experiential marketing pattern." [4] experience in marketing, in order to better promote the sales of products, businesses tend to create a consumer atmosphere in the sales field, such as window design, with every kind of personalized Museum, product exhibition hall or commodity city mall and so on, with music, light, color, sales service and so on, to show its taste, taste and pattern, attract consumer sensory requirements, create consumer climate, feel the corporate culture, stimulate interest, and actively guide consumption.

Cultural Experience Model. Cultural experience marketing is an experiential marketing mode that combines enterprise and product culture into experiential marketing, integrates product and culture effectively, and establishes product and cultural needs through the combination of product and consumer characteristics and consumption needs. Enterprises to actively promote the concept of enterprise culture construction and enterprise culture construction, and development, enterprise culture permeates products production and sales, and even brand trademark design and promotional 
activities such as the whole experience in the marketing process, improve the function of products, outstanding products and the aesthetic and symbolic cultural values, let consumers can feel the concept of corporate culture cultural experience in marketing experience, meet the spirit, the good image of the products and enterprises.

\section{Conclusion}

If modern enterprises want to occupy a place in the fierce market competition, they must satisfy consumers' changing consumption needs, highlight the individualization of market segmentation, and provide consumers with more valuable experience that can meet their needs. Under the guidance of customer oriented marketing, experiential marketing, a new marketing mode, is being pursued by more and more businesses and consumers, and has become the most competitive marketing means of enterprises. Experiential marketing will become the trend of marketing in a certain period of time. It will not only provide new market opportunities for enterprises, but also bring new challenges to enterprises. Therefore, the enterprise should practice the experience marketing in an all-round way, meet the consumer's experience demand, and realize the business goal of the enterprise.

\section{Acknowledgements}

Fund Project: High quality curriculum construction project of Qujing Normal University (YZKC2016001)

\section{Reference}

[1] Y.Z. Xiao and S. Fu: Design and Countermeasure Analysis of Experience Marketing in Enterprise,(2010) No.618, p.52-53. (In Chinese)

[2] Z.H. Zhu: A Brief Analysis of the Main Strategies of Experience Marketing,(2008) No.10, p.48-49. (In Chinese)

[3] R. Liu: Experience Marketing and its Strategy Analysis, Vol.18 (2008) No.1, p.11-13,35. (In Chinese)

[4] F. Wu and C.C. He: Analysis of Experiential Marketing Model Based on Consumer Psychological Demand, (2009) No.578, p.71-74. (In Chinese) 